\title{
Applying a Mental Health Recovery Approach for People from Diverse Backgrounds: The Case of Collectivism and Individualism Paradigms
}

\author{
Samson Tse $\cdot$ Roger M. K. Ng
}

Accepted: 30 April 2014/Published online: 29 May 2014

(C) Springer India Pvt. Ltd. 2014

\begin{abstract}
Western countries have put the mental health recovery approach into practice since the $80 \mathrm{~s}$, and other cultures have started to adopt it into their services. However, the cross-cultural application of the recovery approach has to be addressed, and individualistic-collectivistic values often take center stage in the debate. While people with individualistic value orientations place importance on personal goals, people with collectivistic value orientations see themselves and their goals as an inseparable part of a family or community. However such a simplistic view on the two values may polarize the differences rather than appreciate the intricacies and heterogeneity within and across people and cultures. This brief paper outlines how these two value paradigms may help and hinder recovery on a practical level. The present paper offers a framework for providing culturally responsive mental health service that adequately engages service users and families, thereby generating more dialogues on the topic.
\end{abstract}

Keywords Culture $\cdot$ Serious mental illness $\cdot$ Family

\footnotetext{
S. Tse $(\square)$

Department of Social Work and Social Administration, Faculty of Social Sciences, The University of Hong Kong, 5/F, The Jockey Club Tower, Centennial Campus, Pokfulam Road, Hong Kong, China

e-mail: samsont@hku.hk

R. M. K. Ng

Department of Psychiatry, Kowloon Hospital, 147A Argyle

Street, Kowloon, Hong Kong, China

e-mail:ngmk@ha.org.hk
}

\section{Introduction}

Recovery has been called a 'a deeply personal, unique process of changing one's attitudes, values, feelings, goals, skills and/or roles... a way of living a satisfying, hopeful and contributing life even with the limitations caused by illness' [1, p. 15 italics added]. One of the translations of 'recovery' in Chinese is 復元 (fuyuan), which is a colloquial phrase found in the ancient Chinese text Yijing (易經). 'Yuan' (元) is the primordial 'qi', meaning energy, vitality, or the driving force in life. Thus, the phrase 'recovery' in Chinese means 'regaining vitality and the life-driving force' [2]. Mary O'Hagan, a recovery activist based in New Zealand and the former Mental Health Commissioner adds a communal or relational dimension to mental health recovery from 'It (recovery) mentions the importance of hope and personal and social responsibility. It states that families, communities and people with mental health problems themselves need to be as actively involved in recovery as mental health services' [3, p. 5 italics added]. Recovery approach 'is radically different from the more medically oriented goal of achieving a semblance of normality through cure with the assistance of potentially lifelong medication. While the achievement of cure is more desirable, the former is more achievable and allows greater therapeutic optimism' [4, p. 176]. For more details on benefits on recovery approach, see a recent review by Slade [5].

Although the recovery approach originated in Englishspeaking, Western countries, researchers have been increasingly exploring how to apply mental health recovery for people from culturally and linguistically diverse backgrounds [6-8]. The reasons are twofold. First, the discussion has been sparked by the fact that several nonEnglish speaking countries have adopted the recovery approach-for example, Sweden, Israel, Austria, and, more 
recently, Hong Kong [8]. Second, given worldwide migration and globalization [9], and the unique situations of countries that have indigenous cultures (e.g., Aborigines in Australia; Maori in New Zealand, Tse et al. [10]), it is fairly common for mental health professionals to work with clients from ethnic minority or indigenous backgrounds.

While it is a delight to see the acceptance-slowly but surely-of the recovery approach across the globe, it is imperative that service users and professionals can fit the approach to suit the ideology and belief systems of different cultures [11, 12], without losing the 'embedded social and political assumptions about the nature of recovery' [8, p. 361]. One of the most frequently mentioned issues in applying the recovery approach across cultures is the individualistic-collectivistic paradigm [1214]. The individualistic-collectivistic orientation is one of the most important and fundamental dimensions of cultural variations [15]. In our previous work, we wrote 'As Chinese people place a strong emphasis on collectivism and the maintenance of harmony...it is pivotal to investigate how recovery is redefined and negotiated by individuals in recovery and, importantly, by their family members and caregivers' [2, p. 157, italics added]. In the present paper, 'family' includes biological relatives, spouses, or significant others who are closely related to the person with mental illness, regardless of whether or not they are living together.

\section{The Individualism-Collectivism Paradigm and Recovery}

\section{Unpacking Individualism and Collectivism}

Research has shown that different nations have different mean values of collectivism and individualism. One of the classic examples is Hofstede's culture dimension model going back to 1980s, which concluded that Britain is one of the most individualistic countries, and Pakistan is the least, while India had a score among the middle [16]. In the individualistic value orientation (IVO), the individual places importance on personal goals over those of the group and is traditionally perceived to be a separate and distinguishable entity. Individuals from IVO are less willing to provide informal care and do so out of a sense of necessity [17]. The cultural value of individualism promotes the needs of the nuclear family over the extended family. The key features of individualism are loose relationships, autonomy, and independence. In contrast, individuals with a collectivistic value orientation (CVO) tend to see themselves and their life goals as an inseparable part of a family, community, or tribe. Collectivism is a cultural value in which the extended family is the central concept, and the needs of an individual family member are subordinate to a sense of family responsibilities [18]. Collectivistic families typically exhibit closeness (e.g., sense of responsibility rather than overt emotional expression toward others) and interdependence. The individualism-collectivism (I-C) paradigm has become a frequently used concept in the psychological study of culture and mental health care [5, 19]. Having said that it is important not to oversimplify and dichotomize individualism and collectivism. In many parts of the world, with increasing globalization, pure individualists and collectivists no longer exist. In fact, many individualistic features have been observed in the so called 'collectivistic' society of China [20]. Furthermore since the seminal work of Markus and Kitayama [21], psychologists have examined the variants of individualism-collectivism paradigm for the past 20 years such as the notion of independent or interdependent self-construal. In fact, a person can have both interdependent self-construal and independent self-construal concurrently without having to put individualism-collectivism as bipolar ends.

\section{Unpacking I-C and the Recovery Approach}

Individualism and collectivism are complex constructs. Neither IVO nor CVO is inherently 'good' for people recovering from mental illness (Table 1). For instance, collectivism may slow personal recovery when the family is ashamed by the stigma associated with mental illness [22, 23]. Sadly, family interactions may exert negative social control over people diagnosed with mental illness $[24,25]$. In order to understand how I-C is related to recovery, this section highlights five important features about the concepts of IVO and CVO.

1. There are many kinds of individualism and collectivism $[19,26]$. The constructs of individualismcollectivism can be further delineated into vertical and horizontal dimensions [19, 27]. The vertical dimension incorporates the prominence of hierarchy and command structures in societies such as a remote village in Mainland China. In contrast, horizontal dimension emphasizes the importance of equality in the society. By superimposing the vertical and horizontal components on individualism-collectivism, four dimensions emerge: Vertical individualism, horizontal individualism, vertical collectivism, and horizontal collectivism. The constructs encompass a wide range of psychological concepts such as attitudes, values, and social context. They manifest at the national (e.g., ethnic groups), situational and individual level. Due to the space constraint, the focus for the present paper is on individual level. The I-C paradigm should be considered as one dimension of variation within a 
Table 1 How individualistic-collectivistic values help and hinder recovery ${ }^{1}$

\begin{tabular}{|c|c|c|}
\hline & Individualism & Collectivism \\
\hline $\begin{array}{l}\text { Helps } \\
\text { recovery }^{2}\end{array}$ & $\begin{array}{l}\text { - Service users take center stage in driving the recovery process } \\
{[32,46] \text {. }} \\
\text { - Service users demonstrate great commitment to their own } \\
\text { recovery because their dreams and aspirations are attended to. } \\
\text { - Service users' personal and subjective recovery are legitimate } \\
\text { elements of recovering from mental illness }[33,47] \text {. } \\
\text { - Individualism gives service users the space and freedom to try } \\
\text { various wellness strategies or 'personal medicine' (instead of } \\
\text { being told by family or relatives what they must do). }\end{array}$ & $\begin{array}{l}\text { - Service users experience love, care, respect, and acceptance, } \\
\text { and they receive assistance from the family [48]. } \\
\text { - Reciprocity experiences (e.g., caring for elderly parents, } \\
\text { helping out family chores) in family or wider social contexts } \\
\text { foster recovery [38]. } \\
\text { - Collectivistic intervention works best when service users are in } \\
\text { the early recovery stage, when they need care and acceptance } \\
\text { critical for their recovery. } \\
\text { - Families' step-up support facilitates service users' recovery } \\
\text { when they make recovery leaps (e.g., from part-time } \\
\text { supported employment to a full-time paid job). } \\
\text { - Collectivism nurtures social capital (e.g., more job } \\
\text { opportunities) in the local community that are conducive to } \\
\text { personal recovery [49]. }\end{array}$ \\
\hline $\begin{array}{l}\text { Hinders } \\
\text { recovery }^{2}\end{array}$ & $\begin{array}{l}\text { - The illness-explanatory model associated with individualism } \\
\text { focuses on the individual origins of dysfunction, which tends } \\
\text { to reinforce the medical discourse of mental illness [50]. } \\
\text { - Service users may feel helpless and disabled, receiving little } \\
\text { emotional or tangible support from their family. } \\
\text { - Service users may become self-centered to the extent that they } \\
\text { take on the role of a sick person, expect attention and may } \\
\text { abuse the family or cause conflict among family members, } \\
\text { which is not conducive to the wellbeing of the individual or } \\
\text { family. }\end{array}$ & $\begin{array}{l}\text { - Studies find that cultures with strong collectivistic orientations } \\
\text { have stronger stigma against severe mental illness [51] that } \\
\text { oppress and socially control people affected by mental illness } \\
\text { (e.g., labeling normal emotional reactions as psychiatric } \\
\text { symptoms). } \\
\text { - Collectivism may contribute to an array of dysfunctional } \\
\text { interactions between service users and concerned significant } \\
\text { others, such as overt hostility toward users' behaviors, } \\
\text { hijacking users' recovery goals, over-protectiveness about } \\
\text { what users should do, and overestimates of users' recovery. } \\
\text { - Collectivism can cause increasing conflict between service } \\
\text { users and significant others. Service users feel entrapped when } \\
\text { two parties have different views on matters, such as recovery } \\
\text { goals, use of medication, need for psychiatric hospitalization, } \\
\text { and what to tell and not tell the treating psychiatrist in follow- } \\
\text { up appointments [52, 53]. }\end{array}$ \\
\hline
\end{tabular}

${ }^{1}$ Since recovery is idiosyncratic and complex [13], this analysis is better understood as a resource to inform future discussion and clinical practice

2 The material outlined in this table emerged from a discussion with 11 mental health practitioners (held on 17th January 2013 by ST) and feedback from two individuals with personal experience of mental illness

person. It is therefore more meaningful to focus on specific values and belief systems and their behavioral consequences [26, 28].

Case scenario: Individualism can change according to the social context.

Van Can may be individualistic in his workplace but collectivistic (e.g., eager to hear his parents' opinion) when discussing his medication with the treating psychiatrist.

2. Studies of ethnic migrants community have suggested that parental collectivism values are often transmitted across generations, and the younger generation (e.g., young persons in recovery from mental illness) does not necessarily adopt the individualism of the host country $[17,29]$. The acculturation perspective explains this by saying that parents often work hard to instil collectivistic values as a way to preserve family values and tradition. The implication is that mental health professionals have to promote recovery practice not only among service users but also parents and relatives.

3. Although the literature tends to associate the I-C paradigm with certain cultures and ethnicities (e.g., Chinese and Japanese have a stronger collectivism orientation than Europeans), it is worth noting there are always exceptions. Some researchers have argued that thinking of culture in these polarized terms is neither helpful nor accurate [30]. For example, some Western people think and behave in an Eastern way and vice versa. Furthermore, Asian or Nordic people are often seen as a single ethnic group, but these areas are not culturally homogenous. Members will vary in exposure, experience, social background, and 
geographical settings (e.g., rural vs. urban), all of which influence their values, beliefs, and worldviews.

4. Service users and family need to be supported in the recovery journey regardless if they come from collectivism or individualism backgrounds. Lack of communication between families and professionals is indeed common reason people do not pursue recovery goals [31].

Case scenario: Family worries participating in peer support worker training may precipitate relapse in their loved one [4].

Raji has been a mental health service user for 10 years and is inspired to receive training as a peer support worker. However, her husband is not supportive of her move because he is afraid that the training will cause stress and trigger a relapse of her bipolar illness. While it may be true that Raji's hesitation to pursue treatment is related to the I-O value clash between Raji and her husband, it is also possible that it is because her family has a limited understanding of the recovery process.

5. The links between $\mathrm{I}-\mathrm{C}$ value orientation and recovery are not straightforward. It is not possible to say that either orientation is inherently good or bad for recovery. Table 1 illustrates how the two different orientations may help and hinder recovery.

\section{Proposed Recovery-Oriented Framework to Support Service Users Who Identify with the Collectivistic Value Orientation and Have Supportive Family}

Since the recovery approach is typically described as Westernized and based on an individualistic worldview [3], this section discusses how to use the recovery approach with service users from a collectivistic background. Since this is a challenging and less-understood vision of recovery practices, this section cannot offer a definitive answer or rigid working steps. However, at the very least, this section can promote dialogue on the topic and provide a framework for thinking through the major issues.

\section{Working with Service Users}

- Hear service users'voices. The very core value and vision behind the history of the recovery movement is to let service users take the driver's seat to navigate their recovery journey [32]. Service users' voice and subjective experience have to be heard [33]. Their rights have to be acknowledged and protected. Practitioners can facilitate discussion to explore viewpoints and expectations among various members of the family including the service user. Within a CVO cultural setting or community [34], it probably makes sense to broaden our ordinarily person-centered approach to decision-making to include family members and other influential "natural supports" (e.g., church elders, respected community leaders). Nevertheless, service users with a strong CVO background may find it challenging to articulate their own recovery goals and aspirations.

- Back to the basics: 'Let's talk about it'. Instead of assuming that service users have collectivistic worldviews (again, it greatly depends on the specific social context and individual), practitioners have to discuss the practical meaning of collectivistic (or individualistic) values, their relationships with families, peers and society at large and the proper way to address the collective needs [35, 36]. The I-C value orientation could be part of a comprehensive assessment of service users from culturally and linguistically diverse backgrounds (for a recent review on culural comeptence, see the work by [37]).

- Raise awareness. Mental health professionals have to increase their awareness and cultural sensitivity to appreciate how the I-C concept may help or hinder recovery (Table 1). Professionals may mobilize the wider support network (e.g., supportive family members and peer support workers) to facilitate recovery. In other cases, issues with the family may be part of what is holding back service users. In that case, professionals may help service users untangle the issues they have with their families and pursue what is best for their recovery.

Working with Family or Concerned Significant Others

- Inform family about recovery values and process. Regardless of whether the service user comes from a collectivistic or individualistic background, it is paramount that professionals help family and significant others better understand the principles of recovery, the roles played by family, and the types of recovery-oriented services available. Of course, some families refuse to be involved in the family member's recovery. If that is the case, practitioners can also explore with service users about the wider social network such as workmates or friends met in religious groups. At the very least, even in the absence of any of such network, a dialogue between practitioner and service user will facilitate the service user's reflection and subsequent action. Or in other cases, the family desperately wants assistance coping with the family member's illness, but the service user does not let his/her family have any contact at all with mental health services. 
Table 2 Potential barriers experienced by service users from collectivistic backgrounds who want their family to be involved in the recovery $[31,39,41,43,44,54,55]$

\begin{tabular}{|c|c|c|}
\hline $\begin{array}{l}\text { Level of } \\
\text { barrier }\end{array}$ & Type of potential barriers & Remarks \\
\hline System level & $\begin{array}{l}\text { Lack of leadership support; training curriculum that does not } \\
\text { equip the workforce with adequate knowledge and skills; not } \\
\text { enough time or priority given to family work; hours are not } \\
\text { reimbursed or counted as service outputs; no family room; no } \\
\text { evening or weekend hours. }\end{array}$ & \\
\hline $\begin{array}{l}\text { Practitioners } \\
\text { level }\end{array}$ & $\begin{array}{l}\text { Lack of specialized knowledge and skills; tendency to label } \\
\text { family involvement from dissimilar cultural background as } \\
\text { 'controlling, over-protective'; lack of understanding of } \\
\text { collectivistic value orientation; unsure about the privacy law. }\end{array}$ & $\begin{array}{l}\text { Not every human service worker has to be a family therapist, it } \\
\text { is paramount that workers have basic knowledge and skills to } \\
\text { provide family consultation and assess the need for referrals. } \\
\text { (For a detailed discussion on dealing with the dilemma of } \\
\text { violating service users' right to confidentiality (for a detailed } \\
\text { discussion on dealing with the dilemma of violating service } \\
\text { users' right to confidentiality, see [55] }\end{array}$ \\
\hline $\begin{array}{l}\text { Service users } \\
\text { level }\end{array}$ & $\begin{array}{l}\text { Concern about burdening relatives and family; hard to find a } \\
\text { family member who really cares; fear that family may } \\
\text { disclose something service users feel uncomfortable about. }\end{array}$ & $\begin{array}{l}\text { Service users' desire to involve family may change according } \\
\text { to the recovery stages they are in; recovery is a fluid and non- } \\
\text { linear process. }\end{array}$ \\
\hline $\begin{array}{l}\text { Relatives/ } \\
\text { care-givers } \\
\text { level }\end{array}$ & $\begin{array}{l}\text { Time constraints; caregiving stressors; lack of understanding of } \\
\text { the concept of recovery. }\end{array}$ & $\begin{array}{l}\text { Caregiving stressors refer both to caregiving tasks (e.g., } \\
\text { supervising medications, providing transport) and the } \\
\text { feelings of strain experienced because of those tasks. }\end{array}$ \\
\hline
\end{tabular}

- Cover pertinent issues. In connection to the I-C discourse and recovery, the fundamental issues are: From whom does the service user seek support? How can the family or concerned significant others let the service user stand tall to pursue their recovery dreams? There are benefits to all parties concerned such as reduction in burden of care-giving, enhanced level of wellness within a family when service user is able to realize their life potentials [38, 39]. Mental health professionals may bring up the following topics or scenarios for discussion [40]: oasis of resources and strengths within the service users and the wider family, recovery goals and aspirations, use of medication, conflict resolution when the service user and family have different viewpoints about recovery, and finally stigma and discrimination. When dealing with these difficult topics, one strategy is to find out which person in the family or tribe influences the opinion of the group.

- The mental health workforce needs to improve their skills for working with families. In the author's personal experience of discussion with practitioners, many professionals report feeling grossly undertrained in working with service users from collectivistic backgrounds and incorporating the family. They feel that the majority of the mental health training views mental health as an individual disorder and there is very limited training on working with family to support recovery. 'Joint working between professionals, service users and family members in mental health has been increasingly sophisticated and complex...Involvement of family members has not advanced as far as that of service users' [41, p. 320]. 'The optimal ways to involve families in care, however, remain unclear' [31, p. 7]. Furthermore, the mental health system is sometimes resistant to working with families at system, practitioners, service users and care-givers level (Table 2). 'When asked about including families in treatment or treatment planning, they (co-occurring disorders service agencies) said they did not reach to family members or suggest including them because they wanted to be "client-focused" rather than "familyfocused". This disjuncture is worthy of further study' [42, p. 1228]. The health professionals' apparent reluctance to work with family documented in literature may be related to heavy workload and time constraints, perceived threat to one's power by such family involvement or simply that most of the literatures in psychiatry or mental health are written from an individualistic world view. Strategies at training and organizational levels are required to tackle such resistances, so that recovery goals of service users will be supported by their service providers. For details on recovery approach and family interventions such as family consultation, family education, and psychoeducation see [43-45].

\section{Conclusions}

There is always a degree of individualistic and collectivistic value orientation in us regardless which ethnic background we identify with. The clients we work with are 
no exception. This paper argues the relationship between I$\mathrm{C}$ value orientation and recovery is not straightforward and neither orientation is inherently good nor bad for recovery. The essence of the proposed framework is to provide a culturally responsive mental health service and foster a family-friendly atmosphere that highlights the importance of engaging service users and families. The bottom line is that mental health professionals are ready to collaborate meaningfully with service users including those with strong collectivistic orientation and have supportive family to offer care and interventions that best fit their needs and value orientation. Although individuals affected by mental illness and their family may have different expectations about recovery at times, reconciliation between family and service users is often possible and that it would invigorate commitment from every party to promote recovery.

Acknowledgments We express our gratitude to the mental health workers from Vitality Place (Integrated Community Centre for Mental Wellness), The Society of Rehabilitation and Crime Prevention, Hong Kong who participated in the earlier discussion about the present topic.

Conflict of interest There are no conflicts of interest.

\section{References}

1. Anthony WA. Recovery from mental illness: the guiding vision of the mental health system in the 1990's. Psychosoc Rehabil J. 1993;16:11-23.

2. Tse S, Siu BWM, Kan A. Can recovery-oriented mental health services be created in Hong Kong? Struggles and strategies. Adm Policy Ment Health Ment Health Serv Res. 2011. doi:10.1007/ s10488-011-0391-7.

3. O'Hagan M. Recovery in New Zealand: lessons for Australia? Adv Ment Health. 2004;3(1):5-7.

4. Ng RM, Pearson V, Pang YW, Wong N, Wong N, Chan F. The uncut jade: differing views of the potential of expert users on staff training and rehabilitation programmes for service users in Hong Kong. Int J Soc Psychiatr. 2013;59(2):176-87.

5. Slade M, Amering M, Farkas M, Hamilton B, O'Hagan M, Panther $G$, et al. Uses and abuses of recovery: implementing recovery-oriented practices in mental health systems. World Psychiatr. 2014;13(1):12-20.

6. Fukui S, Shimizu Y, Rapp CA. A cross-cultural study of recovery for people with psychiatric disabilities between US and Japan. Community Ment Health J. 2012;48(6):804-12.

7. Chiu MYL, Ho WWN, Lo WTL, Yiu MGC. Operationalization of the SAMHSA model of recovery: a quality of life perspective. Qual Life Res. 2010;19:1-13.

8. Slade M, Leamy M, Bacon F, Janosik M, Le Boutillier C, Williams $\mathrm{J}$, et al. International differences in understanding recovery: systematic review. Epidemiol Psychiatr Sci. 2012;21:353-64.

9. Segal UA, Elliott D, Mayadas NS. Immigration worldwide: policies, practices, and trends. Oxford: Oxford University Press; 2010.

10. Tse S, Lloyd C, Penman M, King R, Bassett H. Evidence-based practice and rehabilitation: occupational therapy in Australia and New Zealand experiences. Int J Rehabil Res. 2004;27(4):269_ 274.
11. Jacobson N, Farah D. Recovery through the lens of cultural diversity. Psychiatr Rehabil J. 2012;35(4):333-5.

12. Tse S, Cheung E, Kan A, Ng R, Yau S. Recovery in Hong Kong: service user participation in mental health services. Int Rev Psychiatr. 2012;24(1):40-7.

13. Leamy M, Bird V, Le Boutillier C, Williams J, Slade M. Conceptual framework for personal recovery in mental health: systematic review and narrative synthesis. $\mathrm{Br} \mathrm{J}$ Psychiatr. 2011;199(6):445-52.

14. Logan SL, Freeman EM. Health care in the black community: empowerment, knowledge, skills, and collectivism. New York: Haworth Press; 2000.

15. Billing TK, Bhagat R, Babakus E, Srivastava B, Shin M, Brew F. Work-family conflict in four national contexts: a closer look at the role of individualism-collectivism. Int J Cross Cult Manag. 2013. doi:10.1177/1470595813502780.

16. Hofstede G, Bond MH. Hofstede's culture dimensions. An independent validation using Rokeach's Value Survey. J Cross Cult Psychol. 1984;15:417-33.

17. Willis R. Individualism, collectivism and ethnic identity: cultural assumptions in accounting for caregiving behaviour in Britain. $\mathrm{J}$ Cross Cult Gerontol. 2012;27(3):201-16.

18. Tse S, Davies M, Li Y. Match or mismatch: use of the strengths model with Chinese migrants experiencing mental illness: service user and practitioner perspectives. Am J Psychiatr Rehabil. 2010;13(3): 171-88.

19. Triandis HC. Individualism and collectivism. Boulder: Westview Press; 1995.

20. Steele LG, Lynch SM. The pursuit of happiness in China: individualism, collectivism, and subjective well-being during China's economic and social transformation. Soc Indic Res. 2013;114 (2):441-51.

21. Markus HR, Kitayama S. Culture and the self: implications for cognition, emotion, and motivation. Psychol Rev. 1991;98 (2):224-53.

22. Ahmedani B, Kubiak S, Kessler R, de Graaf R, Alonso J, Bruffaerts R, et al. Embarrassment when illness strikes a close relative: a World Mental Health Survey Consortium multi-site study. Psychol Med. 2013;43(10):2191-202.

23. Mak WW, Cheung RY. Psychological distress and subjective burden of caregivers of people with mental illness: the role of affiliate stigma and face concern. Community Ment Health J. 2012;48(3):270-4.

24. Miklowitz DJ, Schneck CD, Singh MK, Taylor DO, George EL, Cosgrove VE, et al. Early intervention for symptomatic youth at risk for bipolar disorder: a randomized trial of family-focused therapy. J Am Acad Child Adolesc Psychiatr. 2013;52(2):121-31.

25. S-M Ng, Y-S Sun. Validation of the concise Chinese level of expressed emotion scale. Social Work Ment Health. 2011;9 (6):473-84.

26. Oyserman D, Coon HM, Kemmelmeier M. Rethinking individualism and collectivism: evaluation of theoretical assumptions and meta-analyses. Psychol Bull. 2002;128(1):3-72.

27. Bhagat R, Segovis J, Nelson T. Work stress and coping in the era of globalization. New York: Routledge; 2012.

28. Brewer M, Chen Y. Where (who) are collectives in collectivism? Toward conceptual clarification of individualism and collectivism. Psychol Rev. 2007;114(1):133-51.

29. McCleary L, Blain J. Cultural values and family caregiving for persons with dementia. Indian J Gerontol. 2013;27(1):178-201.

30. Lawrence V, Murray J, Klugman A, Banerjee S. Cross-cultural variation in the experience of depression in older people in the UK. In: Abou-Saleh MT, Katona C, Kumar A, editors. Principles and practice of geriatric psychiatry. Chichester: Wiley; 2010. p. $518-23$. 
31. Dausch BM, Cohen AN, Glynn S, McCutcheon S, Perlick DA, Rotondi A, et al. An intervention framework for family involvement in the care of persons with psychiatric illness: Further guidance from family forum II. Am J Psychiatr Rehabil. 2012;15(1):5-25.

32. Anthony WA, Ashcraft L. The recovery movement. In: Levin BL, Henessy KD, Petrila J, editors. Mental health services: a public health perspective. New York: Oxford; 2010. p. 465-79.

33. Zisman-Ilani Y, Roe D, Flanagan EH, Rudnick A, Davidson L. Psychiatric diagnosis: what the recovery movement can offer the DSM-5 revision process. Psychos Psychol Soc Integr Approach. 2012. doi:10.1080/17522439.2012.699542.

34. Tse S. Use of the recovery approach to support Chinese immigrants recovery from mental illness: a New Zealand perspective. Am J Psychiatr Rehabil. 2004;7:53-68.

35. Banks C, Tse S, Stewart M, Kazantzis N, Hauraki J, Choummanivong $\mathrm{C}$, et al. Therapy across cultures: a clinical round table discussion about working with people from cultures other than your own. N Z J Psychol. 2006;16:18-23.

36. Tse S, Lloyd CA, McKenna K. When clients are from diverse linguistic and cultural backgrounds. In: McKenna K, editor. Client education: a practical guide for clinical therapists. Sydney: UNSW Press; 2006. p. 307-26.

37. Kirmayer L. Rethinking cultural competence. Transcult Psychiatr. 2012;49(2):149-64.

38. Pernice-Duca F. Family network support and mental health recovery. J Marital Fam Ther. 2010;36(1):13-27.

39. Miklowitz DJ. Bipolar disorder: a family-focused treatment approach. 2nd ed. New York: The Guilford Press; 2008.

40. Meehan TJ, King RJ, Beavis PH, Robinson JD. Recovery-based practice: do we know what we mean or mean what we know? Aust N Z J Psychiatr. 2008;42(3):177-82.

41. Wallcraft J. What has been learned from joint working between mental health professionals, patients and users of psychiatric services, their families and friends? Curr Opin Psychiatr. 2012;25 (4):317-21.

42. EnglandKennedy ES, Horton S. "Everything that I thought that they would be, they weren't:" Family systems as support and impediment to recovery. Soc Sci Med. 2011;73(8):1222-9.

43. Gehart DR. The mental health recovery movement and family therapy, part II: Collaborative, appreciative approach for supporting mental health recovery. J Marital Fam Ther. 2012;38 (3):443-57.

44. Gehart DR. The mental health recovery movement and family therapy, part I: consumer-led reform of services to persons diagnosed with severe mental illness. J Marital Fam Ther. 2012;38(3):429-42.

45. Wallcraft J, Amering M, Freidin J, Davar B, Froggatt D, Jafri H, et al. Partnerships for better mental health worldwide: WPA recommendations on best practices in working with service users and family carers. World Psychiatr. 2011;10:229-36.

46. Deegan P. Recovery: a lived experience of rehabilitation. Psychosoc Rehabil J. 1998;11:11-9.

47. O'Hagan M. Leadership for empowerment and equality: a proposed model for mental health user/survivor leadership. Int $\mathrm{J}$ Leadersh Public Serv. 2009;5(4):1-12.

48. Tse S, Tang J, Kan A. Health Expect. 2012. doi:10.1111/hex. 12014.

49. Lloyd C, Tse S, Deane FP. Community participation and social inclusion: how practitioners can make a difference. Adv Ment Health. 2006;5(3):185-93.

50. Corrigan PW, Watson AC. The paradox of self-stigma and mental illness. Clin Psychol Sci Pract. 2002;9(1):35-53.

51. Papadopoulos C, Foster J, Caldwell K. Individualism-collectivism' as an explanatory devise for mental illness stigma. Community Ment Health J. 2012. doi:10.1007/s10597-012-9534-x.

52. Lam MM, Pearson V, Ng RM, Chiu CP, Law CW, Chen EY. What does recovery from psychosis mean? Perceptions of young first-episode patients. Int J Soc Psychiatr. 2010. doi:10.1177/ 0020764010374418.

53. Ng RM, Pearson V, Lam M, Law CW, Chiu CP, Chen EY. What does recovery from schizophrenia mean? Perceptions of longterm patients. Int J Soc Psychiatr. 2008;54(2):118-30.

54. Deeken JF, Taylor KL, Mangan P, Yabroff KR, Ingham JM. Care for the caregivers: a review of self-report instruments developed to measure the burden, needs, and quality of life of informal caregivers. J Pain Symptom Manag. 2003;26(4):922-53.

55. Solomon P, Molinaro M, Mannion E, Cantwell K. Confidentiality policies and practices in regard to family involvement: does training make a difference? Am J Psychiatr Rehabil. 2012;15 (1):97-115. 